NEW YORE'S STEEL ROADWAY

The laying of a track of broad, flat, steel rails on Murray Street, between Broadway, and Church Street which was accomplished the middle of last December, was the second step in the opening of a new era of transportation in this country. The flrst step was the introduction of automobiles; the second is the building of good roads for them-roads that shall be suitable for horse-drawn vehicles as well.

The steel road, strange as it may seem, was flrst tried in unprogressive Spain, where a section of it two miles long has undergone the abuses of the heaviest kind of wagon traffic for over ten years, and yet has stood the test well. At the end of seven years, the average cost per year of maintaining the sides and center of the roadway was found to be but $\$ 380$, as against $\$ 5,470$ per annum paid to maintain the flint stone paving or surfacing previously used. The wear of the rails themselves was but $0.1 \mathrm{~mm}$., or 0.003 inch a year.

Gen. Roy Stone was the flrst to see the possibilities of this form of road and to advocate its use in this country, which he did most urgently a year ago, in an address before the Automobile Club of America. President Charles M. Schwab, of the United States Steel Corporation, had some rails rolled after Gen. Stone's designs, and presented them to the Automobile Club, in order that it might lay and test them. It was thought that Murray Street offered the severest test ing ground, on account of the heavy trucking through that thoroughfare. Consequently, that was the street chosen in which to make the first test. The rails hava been in use two months now, and teamsters driving through Murray Street have learned the advantage in using them. Our illustration gives a good idea of the appearance of the street at present.

A glance at the cross-sectional cut will show the reader how the roadbed is prepared for laying the rails. Two $18 \times 18$-inch trenches are dug and filled with $11 \%$ inch broken stone laid over a layer of old paving stones, and top-dressed with 3 inches of ane gravel. The gether at their ends with fish plates on the sides and bottom, while $3 / 4$-inch tie rods at intervals keep them parallel and properly spaced. In building a country road, the earth is graded up to the rail on each side and filled in slightly higher in the center, so as to give the general contour shown in the cross-section.

The rails used in Murray Street are 40 feet long and 1 foot wide, with flanges 3 inches wide on the under side and $\%$ inch wide on the top. The rail is $\% / 8$-inch thick near the flanges, and a trifle thicker in the center. The slight flange on each side of the top of the rail tends to keep a wagon wheel from running of with any slight side-pull, while it can nevertheless easily surmount the flange when the driver wishes to run on or off the track. The rails are laid with the alternate joints on opposite sides, similar to those of a railroad track. The distance from center to center is 5 feet, 6 inches. The weight of the rails is 25 pounds to the foot, or 132 tons per mile, and the estimated cost of a mile of track including laying is $\$ 4,000$. Gen. Stone believes, however, that on country roads lighter and narrower rails weighing but 100 tons per mile can be used, and, with steel at $\$ 18$ per ton, as it is in times of depression, this figure can be cut in half. When once built, a road of this type will last a generation if the earthen part of it is kept in repair at slight expense.

Comparative tractive tests have demonstrated that the power required to haul
a wagon on a steel roadway is less than one-fourth that needed on the ordinar stone road. According to the report of a Pittsburg, Pa., engineer, Mr. F. Me berger, who made some tests with 1,350-pound wagon on a steel road, the average drawbar pull per ton was but 3.23 pounds, as against 41 pounds per ton on macadam and from 75 to 10 pounds per ton on hard earth roads, a demonstrated by previous experiments made in Atlanta, Ga., under similar conditions. This means that 12 times as much power is required on macadam as

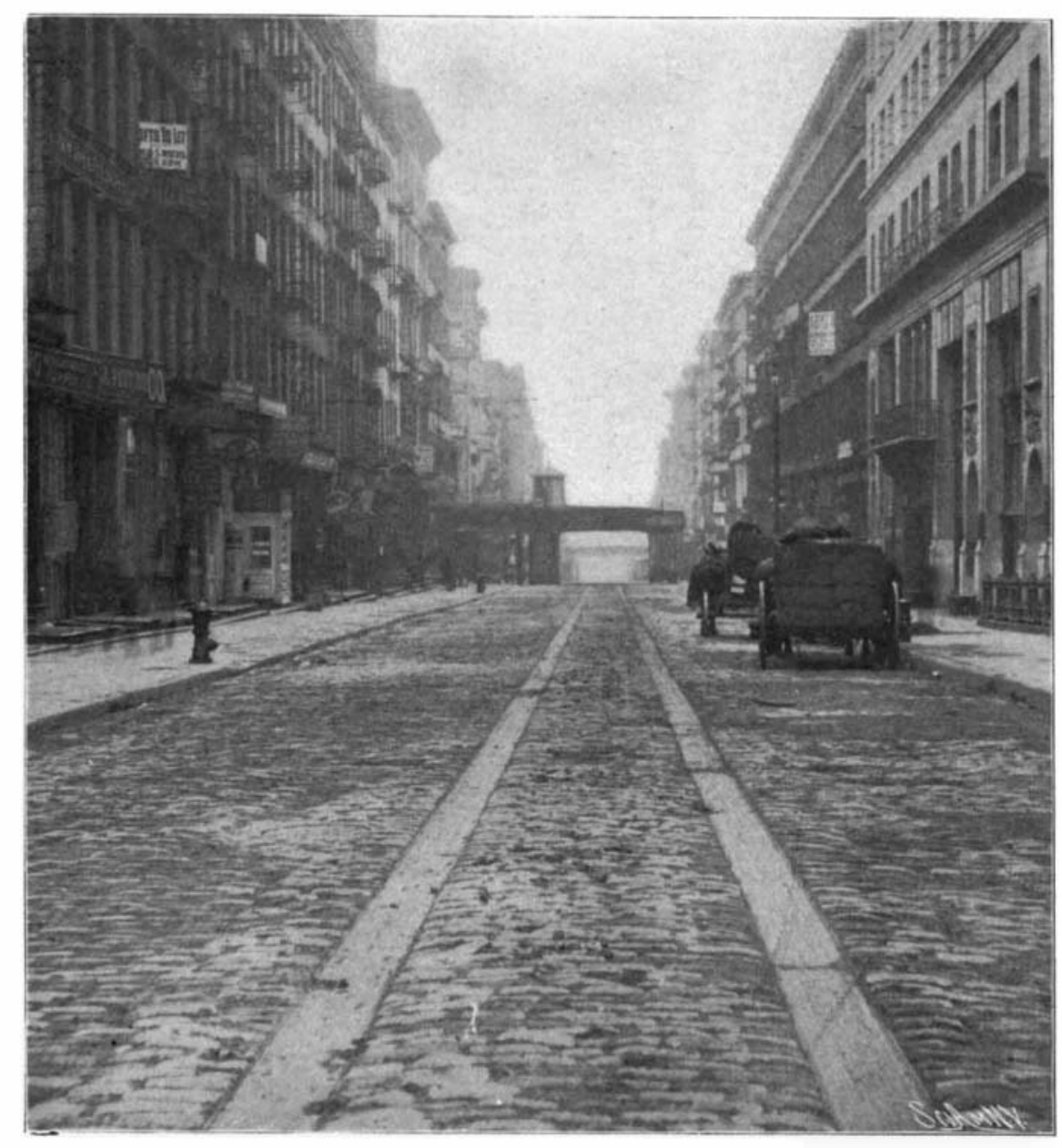

APPEARANCE OF STEEL ROADWAY IN MURRAY STREET, NEW YORK well known, so that after a while there would be con tained within the cavity of the block of ice a quantity of water at a temperature below 32 deg. F., that is to say, below the normal freezing point A further tall of the temperature caused the formation of some more ice, and, consequently, a further increase in the pressure within the block, until at last this pressure became sufficient to burst the ice, and the water was squirted out in a jet. At the same time the pressure was relieved, and thus the freezing point of the water rose to its normal value, so that the water of the jet, being some degrees below this point, immediately froze as it stood.

A somewhat similar occurrence is described in La Nature as having been observed about the middle of December last. D. Crispo, director of the government laboratories at Antwerp, writes that some of the specimens of water in his laboratory froze in the bottles containing them, and one of the bottles presented a most curious appearance, the ice protruding from its neck in a long, smooth worm, capped by the cork, which was forced out. Mr. Crispo thinks that in this case the ice was gradually squeezed out by the increasing pressure in the bottle, behaving like a viscid liquid in consequence of fusion under pressure and subsequent regelation. He does not think it likely that the water was squirted out suddenly. But it must be noted that the case recorded by our correspondent offers something different from this. The ice in the bottle might be squeezed through the unyielding glass nozzle, but if we suppose that the spur on the block of ice of our illustration was gradually forced through a hole in the block we are faced by the difficulty that here the aperture itself, having edges of ice and not of hard glass, would itself be melted by the pressure and would widen out, so that no spur could be formed.

We should be interested to hear the views of some of our readers on this matter.

\section{THE ORANGE IN NORTHERN CALIFORNIA.}

BY ENOS BROWN.
Planting of the first orange tree in the Sacramento Valley was coincident, almost, with its permanent occupation by Americans. Very few of the early miners dreamed of more than a temporary settlement in the land of gold. They had but one purpose-the sudden acquisition of wealth and a return to their distant homes to enjoy it. To most persons the character and resources of the new country were not even conjectured. Geographical science, fifty-four years ago, probably knew less about California than is now universaliy known about the interior of Africa. A few years' residence by the new settlers, however, was sufficient to demonstrate the transcendent charm of the climate and the exuberant fertility of the soil, and to convince them of the wonderful agricultural resources. of the wonderful

Cultivation of the orange as a com mercial proposition in these northerly regions was one of the results of the sequestration of placer mining under the anti-debris law-the golden fruit to supply rescurces that had hitherto been drawn trom golden sands. Progress has been rapid. In 1893, but four cars were shipped from the Sacramento Valley. In 1896, shipments had increased to 81 cars but, in 1901, the total cars shipped out numbered 2,341, a number which fair ly entitles northern California to more than a respectable position in the orange fruit trade.

The city of Oroville, Butte County, may be fairly regarded as the center of orange cultivation in the Sacrament Valley. It is 450 miles north of Los Angeles, and in about the latitude of Philadelphia. Soil and climatic conditions are especially favorable here, and the orange tree reaches its fullest proportions and the fruit its most perfect flavor. The mean annual temperature here, as in all the orange growing coun ties of the valley, averages but four tenths of a degree below that of Los Angeles. So mild is the climate that frost never damages the orange groves
of the locality, neither do pests, which

on steel, and from 23 to 31 times as much on dirt fall in the temperature and to the fact that the granit roads. Experiments also show that the tractive force basin is a better conductor of heat than the ice and required on steel is considerably less than on asphalt. water, a crust of ice formed lining the granite cup, These tigures, coupled with those secured by the and inclosing, together with the ice on the free surgovernment as to the cost per ton-mile for haulage on face, a quantity of unfrozen water in the cavity so formcountry roads, viz., 25 cents, as against 8 cents per ed. Any further freezing of water contained in this cavton-mile in Europe, only go to show how wasteful ity must now create a pressure there, since the ice our present roads are. Of the $\$ 90,000,000$ expended formed occupies more space than the water. But as annually for road transportation of farm products, southern orange growers have ceaselessly to combat ever prove a serious menace. The orange growers
of the Sacramento Valley boast that their fruit ripens two months earlier than in southern California, which lies 7 degrees farther south. By the time the northern orange crop is gathered, shipped, and sold, the south ern orchardist is beginning to pick his fruit.

Throughout the Sacramento and San Joaquin valleys plantations of orange trees are located on the the pressure increases the freezing point falls, as is 
bluffs or foothills, in preference to valleys, which are more liable to be reached by frost. The soil preferred is that of a deep, gravelly, ferruginous, and porous nature. Though thousands of young trees are planted yearly, additional to those in full bearing, the limit of

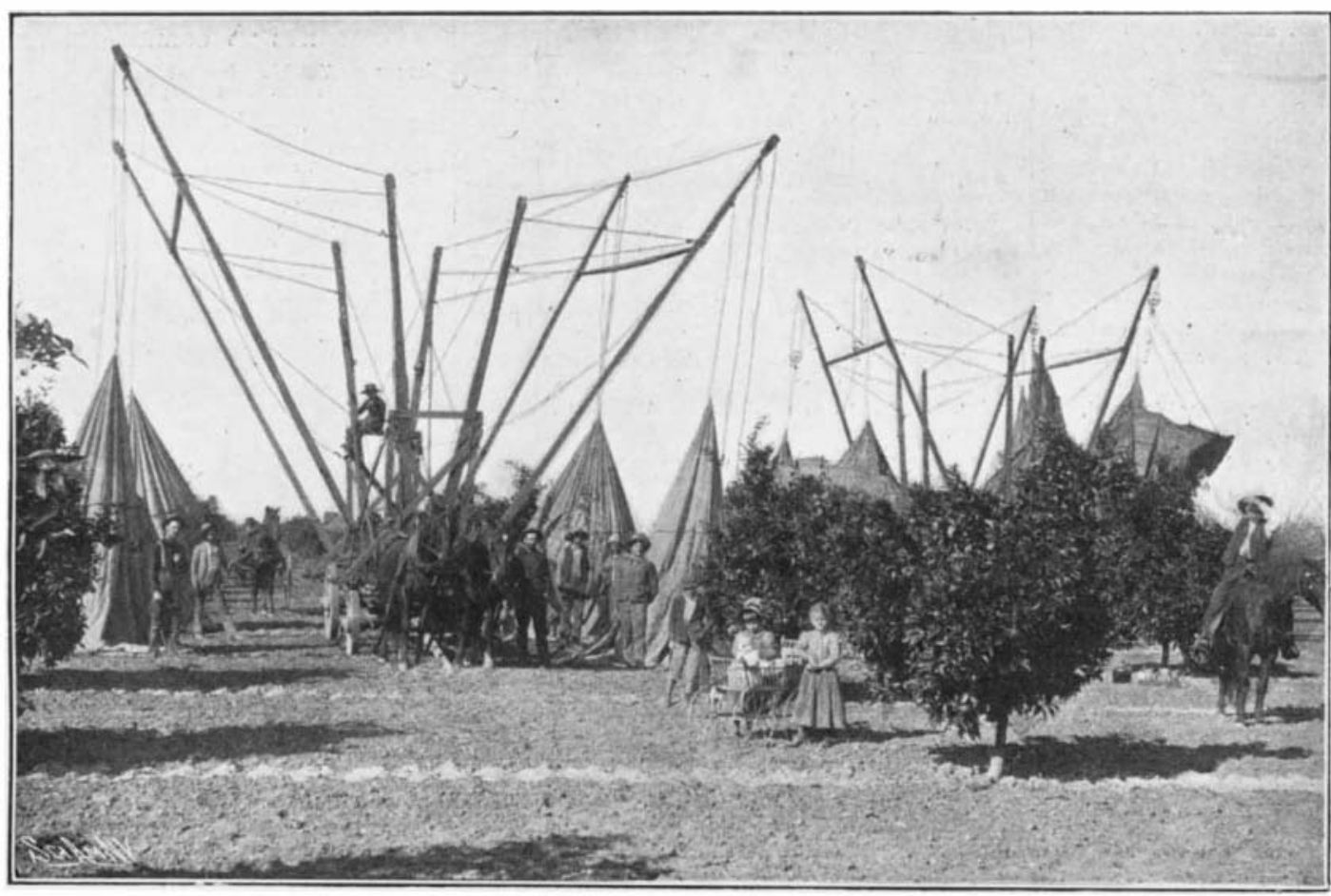

ERECTING TENTS OVER ORANGE TREES BY MACHINERY.

acreage is very far from being reached in California. There is no danger from an oversupply of fruit. The market seems to be boundless.

The methods pursued by the orange cultivators of Butte County are such as any one, even though no experienced in the business, can easily acquire. Ther are no secrets about it. The first requirement is in land selection, about which there need be no difficulty, the only choice being the distance from the shipping point: the nearer the land to this, the more expensive it is naturally. Irrigation is an absolute necessity, owing to the scant summer rains. Water is piped to the lands under a common ditch.

Preparing lands for orange cultivation involves repeated plowings and harrowings both ways, in order to pulverize the soil and extirpate vegetation. The ground should be leveled and hollows filled up. With a gentle slope, a regular flow of irrigating water is assured. Land is plowed to a depth of 7 inches. FerOrange growing exhausts the soil in time, and it is necessary to restore its diminished strength.

Trees are planted 25 feet apart or 70 to the acre. Year old seedlings are procured from the nurseries. In three years these seedlings attain a strong growth, the trunk measuring in diameter about $2 \frac{1}{2}$ inches. The trees, now ready to bud, are pruned. This is done by cutting off all upper branches, leaving whe made in the bark, into which the new bud is inserted. A string tied around the cut keeps the opening closed and the new bud soon begins to show signs of growth. About two buds are inserted in each trunk, all super. fluous growth is checked, and every atom of nourishment is directed toward the development of the new grafts. During budding the stumps are covered with

is harrowed each way to within three feet of the runks. Under the trees the soil is cultivated by gangs of men. February and March is the time for venient places. Ditches are run between the rows and three feet distant from the trees, three ditches between each row. Water is supplied at least once each month each row. Water is supplied at least once each month
and for twenty-four hours at a time. After each irrigation a harrow is run over the ground and the temporary ditches leveled. May, June, July, August, September, and October are devoted to cultivation and general oversight. In November the fruit begins to mature and all else is dropped in order to gather the crop. The gathering season is in full operation by the middle of the month, when the labor of every man, woman and the month, when the lab ripe fruit. This essential matter being concluded, the season is over and the orchardist is permitted a rest.

Three years after budding or six from planting the seedlings the trees begin to bear. The first crop is 280 oranges, the second averages 420 , increasing in number each successive year, provided that cultivation and care is never neglected.

In scientifically conducted plantations the soil is kept absolutely free of extraneous vegetation, every atom of nourishment being required by the tree. The orange tree is a rapid grower and yields prolifically when properly attended to. Neglect is promptly indicated by shrinking and discolored foliage and diminutive fruit. In health it displays every evidence of thrift. When properly cultivated, the orange is one of the most beautiful of trees.

Co-operation among neighboring orchardists provides for handling and shipping the ripe fruit. Uniformity of grade and other advantages are thus secured. A central packing house raceives from the orchards. Th highest grade is 80 to the box, diminishing to 96,112 $126,140,150,176$ and 200 to a package. Packing and papering is done by ordinary help, requiring no especial skill. The grader is a simple contrivance with large hopper into which fruit of all sizes is dumped the sizes being separated in passing down the incline,

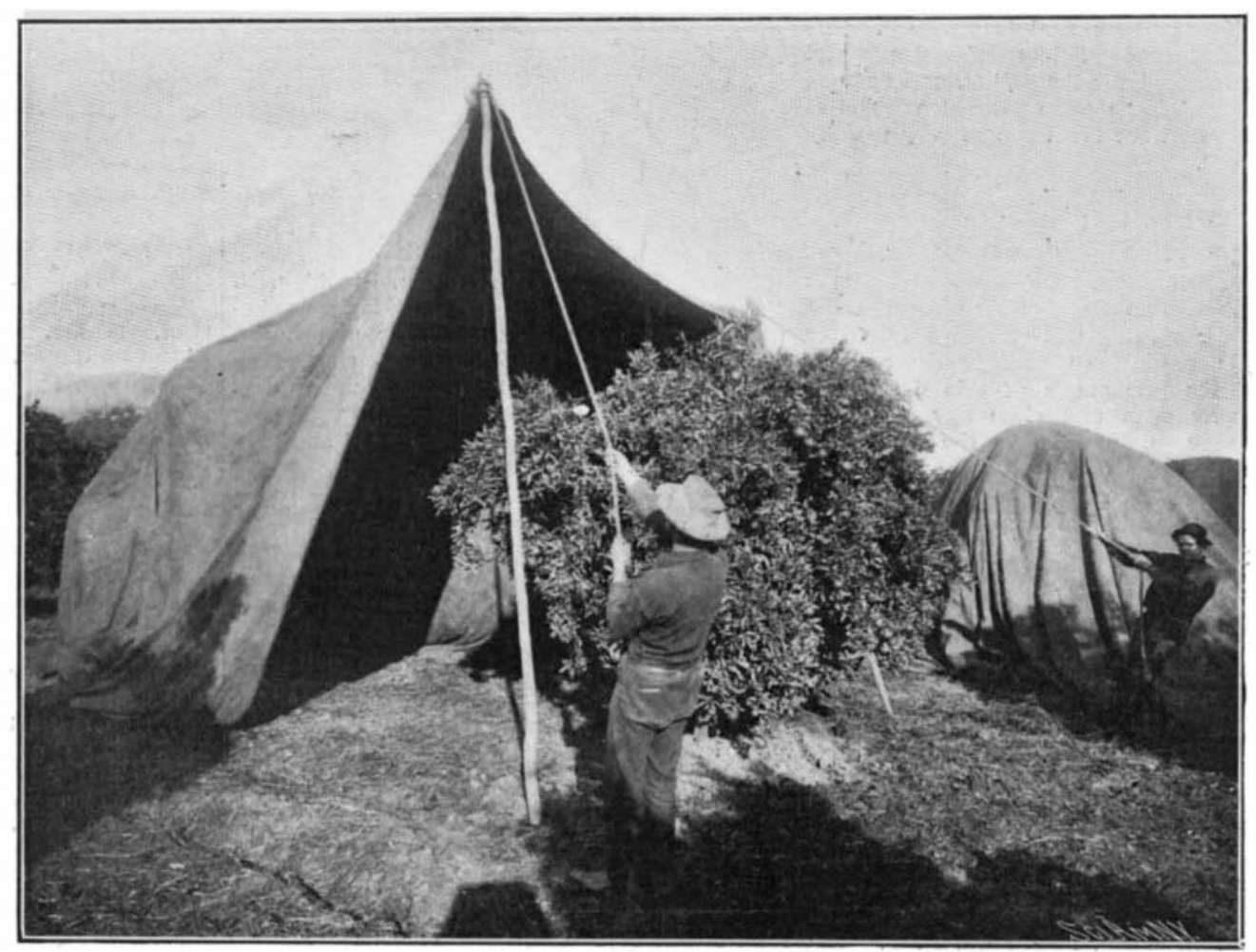

SETTING UP TENTS BY HAND TO PROTECT THE ORANGE TREES.

pruning. All low and superfluous growth is then cut Water is generally conducted to the groves in pipes placed below the surface with openings at con-

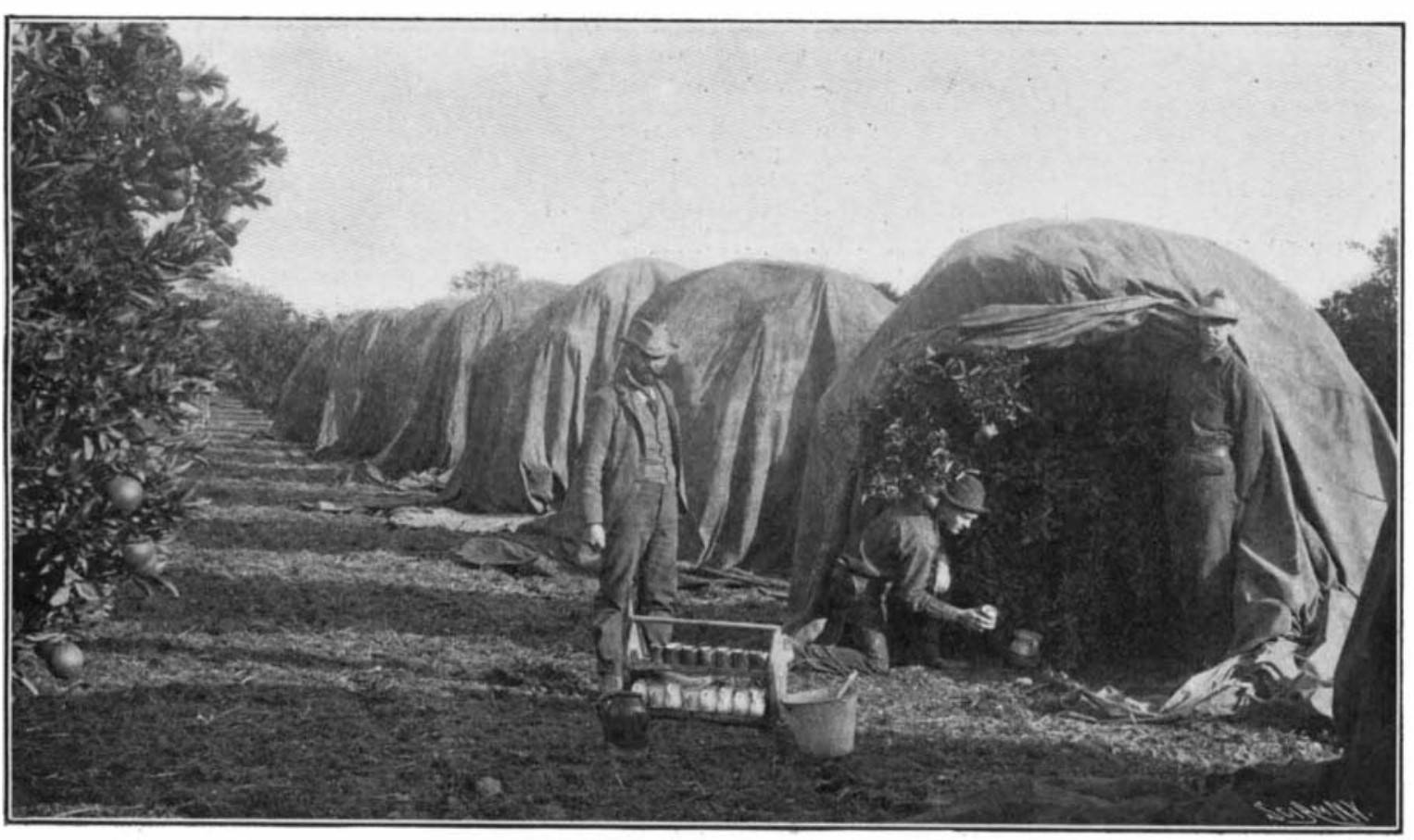

GENERATING POIBONOOS GAS TO RILL BCALE INBECTB. each passing into its proper opening. The oranges cultivated are the Washington navel and Tangarines. The amount of help required in the orchard varies with the seasons. In picking time the number of hands is greatly increased, as it is during the season of pruning. Ordinarily one man to thirty-five acres is the rule.

The cost of starting an orange orchard in the Oro ville district, land at from $\$ 40$ to $\$ 75$ an acre, has bee estimated as follows: Plowing, harrowing both ways, $\$ 60$ an acre; digging holes to set out trees, $\$ 40$; seedlings (80 to one acre), $\$ 48$; cooler for irrigating, abor, per acre $\$ 5$; or a tot abor per acre $\$ 5$; estimated at $\$ 25.50$; third year $\$ 20.50$, and fourth year $\$ 23.80$, fifth year $\$ 26.50$, or a total for five years of $\$ 204.30$. Ordinary cost of clearing land is about $\$ 15$ an acre. Orange lands in full bearing are now selling at $\$ 1,000$ an acre. In the sixth year after planting, an income is to be expected from the orchard, which will increase year after year in proportion to the skill and care displayed in cultivation.

The new Morningside Telephone Company represents an investment of $\$ 300$. 000 and has a capacity for 72,000 wires. It is locate on 124th Street near Seventh Avenue, and has just been opened for use. The switchboard alone cost $\$ 125,000$. It is equipped with a newly patented device, by means of which any of the subscribers or a party line may be called up without ringing the bells of the others. 